\title{
Dual X-Ray Absorptiometry of the Lumbar Spine but not the Hip: Any Problems with a Swiss Policy?
}

\author{
Gerhard W. Goerres ${ }^{*}, 1$, Jaap Swanenburg ${ }^{2}$ and Daniel Uebelhart ${ }^{2}$ \\ ${ }^{1}$ Institute of Medical Radiology, Buergerspital Solothurn/Spital Grenchen soH, Solothurn, Switzerland \\ ${ }^{2}$ Osteoporosis Center, Department of Rheumatology and Institute of Physical Medicine, University Hospital Zurich, \\ Zurich, Switzerland
}

\begin{abstract}
Introduction: Osteoporosis is a growing healthcare problem in societies with aging populations and DXA is increasingly important to evaluate patients at risk and measure effects of osteoporosis treatment. In Switzerland, as in most Western countries, growing expense of public healthcare forces public authorities to take cost-saving action. The restriction of reimbursement for DXA measurement of the hip might impact negatively on patient care.

Methods: We retrospectively evaluated data of 770 patients $(59.3 \pm 14.6$ years, 14 - 91 years; 91 male and 679 female) and analyzed the proportion of patients with low bone mass as based on DXA measurements of a hip/spine combination of measurements or a single measurement of the lumbar spine.

Results: There was a significant number of discordant measurements of T-score values between lumbar spine and total hip compared to concordant measurement results in all patients $(\mathrm{p}<0.0001)$ and in postmenopausal women $(\mathrm{p}<0.0001)$.

Conclusion: DXA measurement of the lumbar spine only may miss correct diagnosis of osteopenia or osteoporosis in a significant number of patients. Therefore, it is important to examine both lumbar spine and hip in order to maintain patient care standards.
\end{abstract}

Keywords: Dual X-ray absorptiometry, bone mineral density, osteoporosis, bone health.

\section{INTRODUCTION}

The measurement of bone mineral density (BMD) using Dual Energy X-ray Absorptiometry (DXA) is a standard method to diagnose osteoporosis and assess fracture risk [14]. Since osteoporosis is a growing healthcare problem in societies with aging populations, DXA is increasingly important to evaluate patients at risk and measure effects of osteoporosis treatment. However, DXA is not suitable for screening large populations, because it is relatively expensive and has limited availability in many countries. In Switzerland, as in most Western countries, growing expense of public healthcare forces public authorities to take costsaving action.

The incidence of hospitalization after fracture of lower extremity and axial skeleton increases exponentially after the age of 65. Fractures of the forearm, vertebral bodies and hip are responsible for $79.3 \% / 74.1 \%$ (female/male) of hospitalized patients with osteoporotic fractures in Switzerland [5].

To date, the Swiss Federal Social Insurance Office regulates that bone densitometry is to be reimbursed by insurance companies for measurement at the lumbar spine additional measurement sites may not be separately reimbursed [6]. In contrast, several national and international societies, such as The International Osteoporosis Foundation, The American Society for Bone and Mineral Research, and The American

*Address correspondence to this author at the Institute of Medical Radiology, Buergerspital Solothurn/ Spital Grenchen soH, Schoengruenstrasse 42, 4500 Solothurn, Switzerland; Tel: +41 03262741 00; Fax: +41 03262741 25; Email: ggoerres_so@ spital.ktso.ch
Association of Clinical Endocrinologists, recommend measurement at the spine and hip. This is in accordance to the official position of the International Society for Clinical Densitometry (ISCD). The correct measurement implies DXA acquisition at more than one site using lowest T-score value as obtained from one of these measurement sites to diagnose low bone mass (i.e. osteopenia/osteoporosis). The inverse conclusion is that DXA-based diagnosis of osteopenia/osteoporosis is not sufficiently reliable if measuring only one site.

Recently, it was suggested that the combination of DXA results obtained from the lumbar spine and femoral neck with selection of the lowest T-Score value does not improve ability for fracture prediction compared with either site alone as previously predicted [7]. Kanis et al. hypothesized that lack of additive value of measuring multiple sites for diagnosis of osteoporosis, as found in their retrospective evaluation of more than 19000 patients from six prospectively studied population-based cohorts, may relate to progressive osteoarthritis with age in the lumbar spine. This implies that hip measurement is more meaningful for assessment of fracture risk. In contrast, the lumbar spine is thought to be valuable for treatment monitoring. However, results of these authors show that, in their population, BMD measurement of the lumbar spine predicted any fracture and any osteoporotic fracture as well as measurement of the femoral neck [7]. To keep in mind that the predictive power of a single measurement may depend on prevalence of the disease in a given population [7]. The IOF recommends diagnostic criteria should be confined to DXA at the femoral neck using a single-reference base [8]. 
Based on the assumption that restriction of reimbursement for DXA measurement of the hip might impact negatively on patient care, we evaluated the proportion of patients with low bone mass as based on DXA measurements of a hip/spine combination of measurements or single measurement of the lumbar spine.

\section{MATERIALS AND METHODS}

\section{Patients}

All electronic files of patients undergoing DXA of the lumbar spine and hip between June and October 2003 at the Osteoporosis Center University Hospital Zurich were evaluated retrospectively. The evaluation was in accordance to ethical guidelines of our institutional review board and use of data for this analysis was approved by the local ethics committee.

\section{DXA Measurements}

All DXA measurements were performed on the supine patient at lumbar spine and non-dominant hip with Hologic QDR $4500 \mathrm{~A}$ and C devices (Hologic Inc., Waltham, MA). The two devices were cross-calibrated using a spine phantom and daily quality controls were performed by the same two experienced technicians during the study period. In 2003 the regions of interest (ROI) at the lumbar spine were placed in the vertebral body L2 - L4 and in the hip a total ROI with additional ROIs in the Ward's triangle, femoral neck, and trochanter. BMD was given as absolute values in $\mathrm{g} / \mathrm{cm}^{2}$, and as $\mathrm{Z}$-score and $\mathrm{T}$-score values. The $\mathrm{T}$-score corresponds to the number of standard deviations from the mean of a gender-matched reference population of young adults, defined as Peak Bone Mass, as provided by the manufacturer. In agreement with the ISCD guidelines, osteopenia or osteoporosis were defined according to lowest measured Tscore value in either spine or hip. Osteopenia, as defined by the WHO classification, corresponds to a T-score value between -1.0 and -2.5 . Osteoporosis was defined as T-score value of -2.5 and lower. Low bone mass is defined as Tscore value $\leq-1.0$ [9]. Measurement of the non-dominant forearm is not routinely acquired in our institution since diagnosis of osteoporosis is based on lumbar spine and hip measurement and $33 \%$ radius is considered to be more valuable in patients wit hyperparathyroidism and for therapy control.

\section{Data Analysis}

The quality of all DXA measurements was assessed visually and scans from patients with lumbar spine and hip measurements were analyzed. All scans with minor quality (e.g. due to metal artefacts) and patients undergoing measurement of the non-dominant forearm were excluded. The $\mathrm{T}$-score values as measured at the lumbar spine, total hip and femoral neck were used for statistical comparisons. It is well known that T-score cannot be used universally in all age groups and it is primarily reserved to evaluate fracture risk in postmenopausal women $[10,11]$. We chose to use T-score values as cut-offs to generate patient subgroups (in postmenopausal women, premenopausal women and males, and young patients) to simplify statistical comparison, since the purpose of this study was not predicting fracture risk in individual patients. The importance of T-score values is only given within the clinical context of an individual patient and according to recommendations for DXA testing for the corresponding age group and gender. Additionally, analysis of frequency distribution was performed in postmenopausal women, where T-score values can be directly linked to fracture risk.

\section{Statistics}

Mean value and standard deviation is given for normally distributed values. The frequencies of T-score $>-1.0$ and Tscore $\leq-1.0$ at lumbar spine and hip or femoral neck, respectively, were calculated for all patients. Additionally, frequency of T-score $>-1.0$ in postmenopausal women was compared to T-score $\leq-1.0$ and $\leq-2.5$. Sign test served to compare differences in the number of concordant and discordant findings between lumbar spine and total hip or femoral neck measurement, for all patients and the subgroup of postmenopausal women, respectively. McNemar test served to compare frequencies of the two possibilities of discordant findings, i.e. normal $\mathrm{T}$-score values at lumbar spine with low T-score values at total hip or femoral neck and low T-score values at lumbar spine with normal T-score values at total hip or femoral neck. Bonferroni correction was done for multiple measurements and p-value of less than 0.005 was considered significant.

\section{RESULTS}

\section{Patients}

The data of 770 patients $(59.3 \pm 14.6$ years, 14 - 91 years; 91 male and 679 female) were analyzed. Patients were sent for various clinical indications, such as suspicion of osteoporosis-related fracture, rheumatologic disease, endocrine disorders, long-term steroid medication, and anorexia nervosa. There was also a group of young patients not likely to have reached peak bone mass (age $14-28$ years, $n=43$ ).

\section{Frequency Distribution and Comparisons}

At the lumbar spine, 549/770 patients (71.3\%) had low bone mass, at the hip 419 patients (total hip region; 54.4\%) and 546 patients (femoral neck region; 70.9\%), respectively (Table $\mathbf{1}$ and Table 2).

Table 1. Number of Patients with T-Score Values Indicating normal Bone Mass, Osteopenia and Osteoporosis for the Three Different Regions of Interest. Number of patients in subgroups with $\mathrm{T}$-score values in the normal range, $\mathrm{T}$-score values $\leq-1.0$ and $>-2.5$, and $\mathrm{T}$-score values $\leq-2.5$ as obtained by DXA at the different measurement sites. All 770 patients of both gender and all age groups are included

\begin{tabular}{|c|c|c|c|}
\hline & $\begin{array}{c}\text { T-score value } \\
\mathbf{> - 1 . 0}\end{array}$ & $\begin{array}{c}\text { T-score value } \\
\mathbf{- - 1 . 0} \text { and }>\mathbf{- 2 . 5}\end{array}$ & $\begin{array}{c}\text { T-score value } \\
\mathbf{- \mathbf { 2 . 5 }}\end{array}$ \\
\hline \hline Lumbar Spine & 221 & 334 & 215 \\
\hline Femoral Neck & 224 & 417 & 129 \\
\hline Total Hip & 351 & 352 & 67 \\
\hline
\end{tabular}


Table 2. Number of Patients with T-Score Values Indicating Normal Bone Mass, Osteopenia and Osteoporosis Splitted for the Different Regions of Interest. Frequency distribution in 770 male and female patients of all age groups as obtained by DXA of the lumbar spine, total hip, and femoral neck splitted for T-score values in the normal range, T-score values $\leq-1.0$ and $>$ -2.5 , and T-score values $\leq-2.5$. In the group of young patients with nutritional problems $(n=43)$ the lumbar spine measurement always corresponded to a T-score value $\leq 1.0$

\begin{tabular}{|c|c|c|c|}
\hline & $\begin{array}{c}\text { Lumbar Spine } \\
\text { T-score value }>-1.0 \\
(n=221)\end{array}$ & $\begin{array}{c}\text { Lumbar Spine } \\
\text { T-score value } \\
\leq-1.0 \text { and }>-2.5 \\
\quad(n=334)\end{array}$ & $\begin{array}{c}\text { Lumbar Spine } \\
\text { T-score value } \\
\leq-2.5 \\
(\mathbf{n}=\mathbf{2 1 5})\end{array}$ \\
\hline $\begin{array}{c}\text { Total Hip } \\
\text { T-score value } \\
>-1.0\end{array}$ & 179 & 140 & 32 \\
\hline $\begin{array}{c}\text { Total Hip } \\
\text { T-score value } \\
\leq-1.0 \text { and }>- \\
2.5\end{array}$ & 40 & 183 & 129 \\
\hline $\begin{array}{c}\text { Total Hip } \\
\text { T-score value } \\
\leq-2.5\end{array}$ & 2 & 11 & 54 \\
\hline $\begin{array}{c}\text { Femoral Neck } \\
\text { T-score value } \\
>-1.0\end{array}$ & 142 & 70 & 12 \\
\hline $\begin{array}{c}\text { Femoral Neck } \\
\text { T-score value } \\
\leq-1.0 \text { and }>- \\
2.5\end{array}$ & 74 & 227 & 116 \\
\hline $\begin{array}{l}\text { Femoral Neck } \\
\text { T-score value } \\
\leq-2.5\end{array}$ & 5 & 37 & 87 \\
\hline
\end{tabular}

\section{Frequency Distribution in all Patients $(n=770)$}

In $23 \%$ of patients lumbar spine and total hip T-score value were in normal range. In $49 \%$ of patients, both measurements indicated low bone mass and in 28\% a discordant finding was present (22\% lumbar spine T-score $\leq$ -1.0 and normal T-score at the total hip; $6 \%$ normal lumbar spine $\mathrm{T}$-score and the total hip T-score $\leq-1.0$ ). There was significant number of discordant findings compared to concordant measurement results $(\mathrm{p}<0.0001)$. The combination of low T-score value at lumbar spine and normal T-score value at total hip was more common than the reversed combination $(\mathrm{p}<0.001)$.

In $18 \%$ of patients, lumbar spine and femoral neck value indicated a T-score value in normal range and in $61 \%$ both measurements a low bone mass. In $21 \%$ a discordant finding was present $(11 \%$ lumbar spine $\mathrm{T}$-score $\leq-1.0$ and normal femoral neck; $10 \%$ normal lumbar spine and femoral neck Tscore $\leq-1.0$ ). There was a significant number of discordant findings compared with concordant measurement results $(\mathrm{p}<0.0001)$. There was no significant difference between frequencies of combination of low T-score value at lumbar spine with normal $\mathrm{T}$-score value at femoral neck and the reversed combination $(\mathrm{p}=.0875)$.

\section{Frequency Distribution in Postmenopausal Women}

In 555 postmenopausal women the distribution for the relationship between lumbar spine and total hip measurements was: in $22 \%$, lumbar spine T-score value and total hip $\mathrm{T}$-score value were normal and in $51 \%$ both measurements indicated low bone mass. In $27 \%$ the finding was discordant (21\% low bone mass at lumbar spine with normal T-score at the total hip, in 6\% lumbar spine T-score normal and low bone mass at the total hip). There were significant number of discordant findings compared with concordant measurement results $(\mathrm{p}<0.0001)$. The combination of low T-score value at lumbar spine with normal total hip T-score value was significantly more common than the reversed combination $(\mathrm{p}<0.0001)$.

In $28 \%$ of patients, lumbar spine $\mathrm{T}$-score and femoral neck T-score values indicated normal bone mass and in $17 \%$ both measurements indicated low bone mass. In 55\% a discordant finding was present $(54 \%$ low bone mass at lumbar spine and normal T-score value at femoral neck; in $0.5 \%$ lumbar spine $\mathrm{T}$-score value was normal and the femoral neck showed low bone mass). There were significantly more discordant findings than concordant measurement results $(\mathrm{p}<0.0001)$. In most patients with discordant measurement results, lumbar spine T-score value was low and femoral neck value was in normal range $(\mathrm{p}<0.0001)$.

Omitting the hip as a measurement site in 555 postmenopausal women impacts on final DXA-based diagnosis as follows: in case of a normal BMD measurement result at lumbar spine $(\mathrm{n}=157), 32$ postmenopausal women $(20 \%)$ would have been missed with low bone mass at total hip (2 osteoporosis, $1 \%$ ) and 57 patients (36\%) with low bone mass at femoral neck (3 osteoporosis, $2 \%$ ).

\section{DISCUSSION}

The data of this retrospective evaluation suggest measurement of the lumbar spine only may miss correct diagnosis of osteopenia or osteoporosis in a significant number of patients and in up to $37 \%$ of postmenopausal women. Therefore, we feel it is important to examine both lumbar spine and hip as suggested by several international societies, in order to maintain patient-care standards.

Switzerland has approximately 7.6 million inhabitants. In 20081.4 million women and 1.2 million men were aged 50 and older. Based on previous reports, about 1 in 3 women and 1 in 5 men over 50 will experience osteoporotic fractures [12-14]. Identifying and treating patients at risk of fracture can help reduce long-term costs. It has been shown that treatment of established osteoporosis is cost-effective irrespective of age, as it reduces risk of vertebral and nonvertebral fractures $[15,16]$. In a recent Swiss study, costeffectiveness was shown in osteoporosis treatment in postmenopausal women aged 65 and older undergoing DXA testing [17]. Furthermore, recent data suggest incidence of osteoporotic fractures can be reduced in aging populations when patients are correctly diagnosed and treated [18]. However, it is not possible to prove with our data that 
improved diagnostic accuracy would also translate into improved treatment strategies and consequently in a reduced fracture rate. In a recent study it has been shown that in Switzerland - one of the countries with the highest risk for osteoporotic fractures - the 10 year risk of a major osteoporotic fracture can rise up to $24 \%$ in women depending on clinical risk factors and age [19]. Furthermore, in patients with similar clinical risk profile the risk increases when bone mass decreases. This underlines a role of DXA for BMD measurement to enhance risk assessment. In Switzerland, the cost of treatment will be paid by insurance companies in patients with proven osteoporosis. DXA measurement is one possibility to verify osteoporosis. Therefore, the decision of the Swiss Federal Social Insurance Office to commit insurance companies to only reimburse measurement at lumbar spine may reduce test efficiency and diagnostic power of DXA. In the light of possible future costs due to osteoporosis, the attempt to reduce health expenses by limiting the cost of DXA may be of limited use. However, it has been shown that combining results of DXA measurement of the lumbar spine and femoral neck does not increase predictive ability for osteoporotic fracture compared with either site alone and that the use of a femoral neck region alone is sufficient [7]. The International Osteoporosis Foundation recommends that diagnostic criteria should be confined to the femoral neck as a single measuring site using a single reference base [8]. In contrast, in patients undergoing treatment a lumbar spine measurement may be of more value for monitoring since the spine is considered to be the most responsive site to pharmacologic intervention [7]. It is for these reasons that we feel both measurement sites should be included on DXA testing.

In order to convince health insurance companies as payers to also fund the second part of DXA, the gain has to be demonstrated in terms of reduced fracture rate leading to fewer treatments and finally reduced costs in patients at the long term. This in turn could be addressed in a prospective study assessing the outcome of patients undergoing measurement of one or two sites and monitoring treatment decisions based on DXA measurement. Such study would raise ethical questions. Since the correct assessment of bone density (according to ISCD standards) involves the measurement of two measuring sites the examiner is forced to perform DXA according to this standard. Another problem is legal implications for the examiner. From the juristic point of view it is not justifiable to ask the patient to pay for one of the two measurements, since this would imply shortchanging the patient in his affliction. Self-pay by patients to obtain additional testing would not be allowed even if a patient would desire to pay for the second measurement.

Results of DXA are only part of patient assessment and clinical estimation of risk for fractures with risk scores including age, sex, previous and present height, previous fracture, family history, medications, lifestyle and dietary habits, and medical history are important factors. Decision on treatment is based on an overall impression in an individual patient. However, it has recently been shown that results of DXA testing can change estimation of risk for fractures as based on clinical information and that such change can be observed already for patients with BMD values indicating osteopenia [19].
We feel that this work is a further preliminary step in addressing the problem of measuring decreased bone density in at risk populations and the possible impact of DXA on treatment decisions. Additional investigations should assess how DXA results would influence treatment decisions and how this would reduce the cost of care.

DXA measurement of the lumbar spine only may miss correct diagnosis of osteopenia or osteoporosis in a significant proportion of patients. Therefore, it is important to examine both lumbar spine and hip, as suggested by several international societies, in order to maintain patient care standards. Reduction of refunds for DXA-scanning as a tool to save expenses for public health care might have negative effects on the population.

\section{ACKNOWLEDGEMENTS}

The authors would like to thank Leanne Pobjoy for her help in preparing the manuscript.

\section{REFERENCES}

[1] Kanis JA. Assessment of fracture risk and its application to screening for postmenopausal osteoporosis: synopsis of a WHO report. WHO Study Group. Osteoporos Int 1994; 4: 368-81.

[2] Cummings SR, Black DM, Nevitt MC, et al. Bone density at various sites for prediction of hip fractures. The Study of Osteoporotic Fractures Research Group. Lancet 1993; 341: 72-5.

[3] NIH Consensus Development Panel on Osteoporosis Prevention, Diagnosis, and Therapy. Osteoporosis prevention, diagnosis, and therapy. JAMA 2001; 285: 785-95.

[4] Leib ES, Lewiecki EM, Binkley N, et al. Official positions of the International Society for Clinical Densitometry. J Clin Densitom 2004; 7: 1-6.

[5] Lippuner K, Golder M, Greiner R. Epidemiology and direct medical costs of osteoporotic fractures in men and women in Switzerland. Osteoporos Int 2005; 16 (Suppl 2): S8-S17.

[6] Verordnung des EDI über Leistungen in der obligatorischen Krankenpflegeversicherung. Stand 1. Januar 2008 p. 75. http:// www.admin.ch/ch/d/sr/8/832.112.31.de.pdf [Last visited Nov 26 2008].

[7] Kanis JA, Johnell O, Oden A, et al. The use of multiple sites for the diagnosis of osteoporosis. Osteoporos Int 2006; 17: 527-34.

[8] Kanis JA, Glüer CC. An update on the diagnosis and assessment of osteoporosis with densitometry. Committee of Scientific Advisors, International Osteoporosis Foundation. Osteoporos Int 2000; 11: 192-202.

[9] Leib ES, Lewiecki EM, Binkley N, et al. International Society for Clinical Densitometry. Official positions of the International Society for Clinical Densitometry. J Clin Densitom 2004; 7: 1-6.

[10] Assessment of fracture risk and its application to screening for postmenopausal osteoporosis. Report of a WHO Study Group. WHO Tech Rep Ser 1994; 843: 1-129.

[11] Hans D, Downs RW Jr, Duboeuf F, et al. Skeletal sites for osteoporosis diagnosis: The 2005 ISCD Official Positions. International Society for Clinical Densitometry. J Clin Densitom 2006; 9: 15-21.

[12] Melton LJ, 3rd, Atkinson EJ, O'Connor MK, et al. Bone density and fracture risk in men. J Bone Miner Res 1998; 13: 1915-23.

[13] Melton LJ, 3rd, Chrischilles EA, Cooper C, et al. Perspective. How many women have osteoporosis? J Bone Miner Res 1992; 7: 1005 10.

[14] Kanis JA, Johnell O, Oden A, et al. Long-term risk of osteoporotic fracture in Malmo. Osteoporos Int 2000; 11: 669-74.

[15] Kanis JA, Burlet N, Cooper C, et al. European guidance for the diagnosis and management of osteoporosis in postmenopausal women. Osteoporos Int 2008; 19: 399-428.

[16] Kanis JA, Borgstrom F, Zethraeus N, et al. Intervention thresholds for osteoporosis in the UK. Bone 2005; 36: 22-32. 
[17] Schwenkglenks M, Lippuner K. Simulation-based cost-utility analysis of population screening-based alendronate use in Switzerland. Osteoporos Int 2007; 18: 1481-91.

[18] Jaglal SB, Weller I, Mamdani M, et al. Population trends in BMD testing, treatment, and hip and wrist fracture rates: are the hip fracture projections wrong? J Bone Miner Res 2005; 20: 898-905.
[19] Lippuner K, Johansson H, Kanis J.A., et al. FRAX assessment of osteoporotic fracture probability in Switzerland. Osteoporosis Int 2010; 21(3): 381-9.

Received: August 13, 2009

Revised: November 16, 2009

Accepted: November 18, 2009

(C) Goerres et al.; Licensee Bentham Open.

This is an open access article licensed under the terms of the Creative Commons Attribution Non-Commercial License (http://creativecommons.org/licenses/bync/3.0/), which permits unrestricted, non-commercial use, distribution and reproduction in any medium, provided the work is properly cited. 